\title{
A CAPACIDADE PROCESSUAL DOS ANIMAIS NO BRASIL E NA AMÉRICA LATINA
}

\author{
ANIMAL STANDING IN BRAZIL AND LATIN AMERICA \\ LA CAPACIDAD PROCESAL DE LOS ANIMALES EN BRASIL Y AMERICA LATINA
}

HERON GORDILHO

https://orcid.org/0000-0001-8485-3729 / http://lattes.cnpq.br/9247033382457379 / heron@ufba.br Universidade Federal da Bahia - UFBA

Salvador, BA, Brasil.

VICENTE de PAULA ATAIDE JUNIOR

http://orcid.org/0000-0003-4995-9928 / http://lattes.cnpq.br/8067162391395637 / vicente.junior@ufpr.br Universidade Federal do Paraná - UFPR Curitiba, PR, Brasil.

\begin{abstract}
RESUMO
O presente artigo de revisão utiliza o método lógico-sistemático para analisar a capacidade processual dos animais, considerada em sentido amplo, no Brasil e na América Latina. Inicialmente, o artigo apresenta os principais precedentes dos tribunais latino-americanos, que reconhecem os animais como sujeitos de direito e com capacidade de defender em juízo interesses próprios. Em seguida, revisa o conceito de capacidade processual no Direito brasileiro, em sua tríplice configuração. Na sequência, analisa o Decreto federal 24.645/1934 para demonstrar que os animais possuem capacidade de ser parte processual, desde que devidamente assistidos por seus substitutos legais, pelas sociedades protetoras ou pelo Ministério Público. Por fim, após constatar a omissão doutrinária sobre o tema, analisa as vantagens e desvantagens em se atribuir capacidade de ser parte aos animais.
\end{abstract}

Palavras-chave: Direito Animal; Decreto 24.645/1934; Capacidade de ser parte dos animais; Capacidade processual dos animais; Habeas Corpus em favor de animais.

\begin{abstract}
This review essay uses the logical-systematic method to analyze the standing for animals, considered in a broad sense, in Brazil and Latin America. Initially, the essay presents the main precedents of Latin American courts, which recognize animals as subjects of law and with the capacity to defend their own interests in court. Then, it reviews the concept of standing in brazilian law, in its triple configuration. Then, it analyzes Federal Decree 24.645/1934 to demonstrate that the animals have the standing, as long as they are properly assisted by their legal substitutes, by protective societies or by the public attorney. Finally, after verifying the doctrinal omission on the subject, it analyzes the advantages and disadvantages of attributing the standing for the animals.
\end{abstract}

Keywords: Animal Law; Decree 24.645/1934; Animal standing; Animal capacity to be in court; Habeas Corpus for animals.

\section{RESUMEN}

Este artículo de revisión utiliza el método lógico-sistemático para analizar la capacidad procesal de los animales, considerado en un sentido amplio, en Brasil y América Latina. Inicialmente, el artículo presenta los principales precedentes de los tribunales latinoamericanos, que reconocen a los animales como sujetos de derecho y con la capacidad de defender sus propios intereses en los tribunales. Luego, revisa el concepto de capacidad procesal en el derecho brasileño, en su configuración tríplice. Luego, analiza el Decreto federal 24.645/1934 para demostrar que los animales tienen la capacidad de ser parte procesal, siempre que estén debidamente asistidos por sus sustitutos legales, por sociedades protectoras o por el Ministerio Público. Finalmente, después de verificar la omisión doctrinal sobre el tema, analiza las ventajas y desventajas de atribuir la capacidad de ser parte de los animales.

Palabras clave: Derecho animal; Decreto 24.645/1934; Capacidad de ser parte de los animales; Capacidad procesal de los animales; Habeas Corpus a favor de los animales. 


\section{SUMÁRIO}

INTRODUÇÃO; 1 PRECEDENTES DE DIREITO ANIMAL NA AMÉRICA LATINA; 2 A CAPACIDADE PROCESSUAL NO DIREITO BRASILEIRO EM SUA TRÍPLICE CONFIGURAÇÃO; 3 O DECRETO 24.645/1934 E A CAPACIDADE PROCESSUAL DOS ANIMAIS NO BRASIL; 4 VANTAGENS E DESVANTAGENS EM SE ATRIBUIR CAPACIDADE PROCESSUAL AOS ANIMAIS; CONCLUSÃO; REFERÊNCIAS.

\section{INTRODUÇÃO}

O presente artigo reflete sobre a capacidade dos animais de defender em juízo, em nome próprio, os direitos que the são assegurados pelo ordenamento jurídico brasileiro e pelo de alguns países latino-americanos, como a Argentina e a Colômbia.

Não se pretende aqui revisitar as diversas teorias de Direito Animal, tema sobre o qual muito já se escreveu, nem debater sobre os pressupostos ético-filosóficos dos seus institutos. ${ }^{1}$

Trata-se de um artigo de revisão que utilizará o método lógico-sistemático com o objetivo de demonstrar que animais são sujeitos de direitos, dotados de capacidade de ser parte em uma relação jurídica processual.

0 artigo está estruturado em quatro capítulos.

O primeiro analisa os avanços da jurisprudência sulamericana a partir dos precedentes que admitem os animais como sujeitos de direito.

O segundo capítulo passa em revista os conceitos que orbitam a capacidade processual no Direito brasileiro, em sua tríplice configuração, como pressuposto teórico para a incursão no terceiro capítulo.

Nesse, demonstra-se que o Decreto federal brasileiro 24.645/1934 continua vigente, ainda que parcialmente, a despeito de sua aparente ab-rogação pelo Decreto 11 , de 18 de

\footnotetext{
${ }^{1} 0$ material já publicado, principalmente em língua inglesa, sobre a filosofia e a ética animais é inesgotável. Mas, dois autores - e duas obras - costumam ser indicados como os representantes dos principais movimentos filosóficos-animalistas: Peter Singer, líder do benestarismo, a partir do livro Animal Liberation, de 1975; e Tom Regan, expoente do abolicionismo, a partir do livro The Case for Animal Rights, de 1983. Mas não pode deixar de ser citado o abolicionismo radical de Gary Francione, já nos anos 90 , principalmente a partir da obra Animals, Property and the Law, de 1995. Mais recentemente, uma postura intermediária, a partir da teoria política, pode ser encontrada com Sue Donaldson e Will Kimlicka, em seu Zoopolis: a Political Theory of Animal Rights, de 2011. Da produção original em língua portuguesa, vale a pena consultar as obras A Hora dos Direitos dos Animais, do professor lusitano Fernando Araújo, de 2003, que aborda as principais discussões filosóficas sobre os animais, com ampla varredura de quase tudo o que se escreveu sobre o assunto até então, e Direito dos Animais: Fundamentação e Novas Perspectivas, de 2008, do professor brasileiro Daniel Braga Lourenço, que também procede a um alentado levantamento das premissas filosóficas do Direito Animal.
} 
janeiro de 1991, e que é possível estabelecer o acesso à justiça aos animais, por meio de representantes processuais.

Por fim, o artigo analisa se esse acesso à justiça traz efetividade à proteção dos animais como sujeitos de direitos ou se não passa de mero discurso simbólico, sem qualquer melhoramento na condição de vida dessas criaturas.

\section{PRECEDENTES JUDICIAIS DE DIREITO ANIMAL NA AMÉRICA LATINA}

O Direito Animal pode ser conceituado como “o conjunto de regras e princípios que estabelece os direitos dos animais não-humanos, considerados em si mesmos, independentemente da sua função ambiental ou ecológica."2

A doutrina anglo-saxônica tem sido a principal referência em Direito Animal no mundo moderno e a legislação de alguns países europeus tem avançado bastante ao reconhecer que os "animais não são coisas", mas "seres sensíveis". ${ }^{3}$

Quando se fala em precedentes judiciais, todavia, são os tribunais latinoamericanos que têm tomado as decisões mais revolucionárias, reconhecendo não apenas que os animais são sujeitos de direito, mas que são dotados da capacidade para defender direitos próprios em juízo. $^{4}$

O caso Suiça v. Gavazza foi o primeiro precedente em que um animal foi reconhecido por um tribunal como sujeito de direito dotado da capacidade de ser parte. ${ }^{5}$

Em 19 de setembro de 2005, um grupo formado por membros do Ministério Público, sociedades protetoras, professores e estudantes de direito impetrou um habeas corpus na $9^{a}$

\footnotetext{
${ }^{2}$ ATAIDE JUNIOR, Vicente de Paula. Introdução ao Direito Animal Brasileiro. Revista Brasileira de Direito Animal, v. 13, n. 3, set./dez. 2018. p. 50.

${ }^{3}$ A Áustria foi pioneira em incluir, no seu Código Civil, em 1988, um dispositivo afirmando que os animais não são coisas (tiere sind keine sachen), protegidos por leis especiais (\$285a ABGB); no mesmo sentido, em 1990, foi inserido o \$90a no BGB alemão; em 2003, também no art. 641 a do Código Civil suíço; de forma diferenciada foi a alteração do Código Civil francês, em 2015, dispondo, em seu art. 515-14, que os animais são seres vivos dotados de sensibilidade (Les animaux sont des êtres vivants doués de sensibilité.); na mesma linha do direito francês, mudou o Código Civil português, em 2017, estabelecendo que os animais são seres vivos dotados de sensibilidade e objeto de proteção jurídica em virtude da sua natureza (art. $201^{\circ}-\mathrm{B}$ ).

${ }^{4}$ THE ECONOMIST. 18 de dezembro de 2018. Seção internacional da edição impressa sob o título "Eles possuem direitos?". Disponível em: https://www.economist.com/international/2018/12/22/graduallynervously-courts-are-granting-rights-to-animals. Acesso em: 15 jan. 2020.

${ }^{5}$ CRUZ, Edmundo. Suíça-Habeas Corpus. Tradução: Carlos de Paula. Animal Legal \& Historical Center, Michigan State University. Disponível em: https://www.animallaw.info/case/suica-habeas-corpus. Acesso em: 5 jan. 2020.
} 
Vara Criminal da Comarca de Salvador, Estado da Bahia, em favor da chimpanzé-fêmea de nome "Suíça", que vivia em uma jaula do Zoológico Público daquela cidade.

O Juiz de Direito Edmundo da Cruz, no dia 27 do mesmo mês, aceitou o writ, intimando o diretor do zoológico, Telmo Gavazza, para prestar informações sobre a situação do animal, na condição de autoridade coatora. ${ }^{6}$

Ao aceitar o writ e determinar a notificação da autoridade coatora, quando todos esperavam que ele indeferisse liminarmente a ação judicial, o juiz brasileiro rompeu com uma forte tradição jurídica, de inspiração kantiana, ${ }^{7}$ criando o primeiro precedente judicial do mundo moderno, no qual um animal estabelece uma relação jurídica processual (direito de ação) com um ser humano, na condição de autor e titular de um direito material (o direito de liberdade corporal ou direito de ir e vir). ${ }^{8}$

É que no habeas corpus, o titular do direito é o próprio paciente e, embora a chimpanzé-fêmea Suíça tenha falecido antes do julgamento do pedido, ${ }^{9}$ na decisão que extinguiu o processo, sem resolução de mérito, pela perda do objeto ou do interesse processual, o juiz Edmundo Cruz reafirmou a possibilidade de um chimpanzé ser sujeito de direito, sob o fundamento de que o Direito não pode ser estático e que deve evoluir de acordo com os novos valores sociais. ${ }^{10}$

Em outro caso, nos idos de 12 de julho de 2010, no caso Ministério Público, Associação Terra Verde Viva e Célula-Mãe v. Circo Portugal, a juíza Ana Conceição Ferreira, da $21^{\text {a }}$ Vara Cível e do Consumo de Salvador/BA, decidiu, liminarmente, em ação civil pública, que as

${ }^{6}$ GORDILHO, Heron. Wildlife and the Brazilian Abolitionist Movement. Michigan State University Journal of Animal Law, v. 5, p. 2009. 71, Disponível em: https: / /www.animallaw.info/sites/default/files/Journal\%20of\%20Animal\%20La w\%20Vol\%205.pdf. Acesso em: 5 jan. 2020.

${ }^{7}$ Para Kant, "[...] só existem relações jurídicas entre homens; nunca entre um homem e um ser que só tenha direitos (Deus); ou um ser que só tenha deveres (servos e escravos); ou um ser que não tenha direitos nem deveres (animais)." (KANT, Immanuel. Doutrina do Direito. São Paulo: Ícone, 1993. p. 59).

8"Mesmo assim, os acadêmicos e advogados do Brasil demonstraram a força do Direito de uma maneira nunca sonhada anteriormente, exercendo uma forte influência na defesa dos direitos dos animais." (REGAN, Tom. Nação do Direito Animal. Revista Brasileira de Direito Animal, v. 1, n. 1, 2006. Disponível em: https: / / portalseer.ufba.br/index.php/RBDA/article/view/10236/7292. Acesso em: 2 jan. 2020).

${ }^{9}$ Segundo Steven Wise, “Eu acredito que mesmo com a morte de Suíça (a chimpanzé) o tema continuará sendo discutido, especialmente nas salas das faculdades de direito, visto que muitos colegas, procuradores, estudantes e entidades manifestaram sua opiniões, buscando fazê-las prevalecer. 0 assunto não morrerá com esse writ, certamente continuando por permanecer controverso." (WISE, Steven. O reconhecimento aos chimpanzés do direito de utilizar os writs do Habeas Corpus e do De Homina Replegiando. Revista Brasileira de Direito Animal, v. 6, n. 9, 2011. Disponível em: https: / /portalseer.ufba.br/index.php/RBDA/article/view/11741/8392. Acesso em: 2 jan. 2020).

${ }^{10}$ CRUZ, Edmundo. Suíça-Habeas Corpus, passim. 
elefantas Guida e Maia são sujeitos de direito, pelo que determinou a transferência delas para um santuário na cidade de Minas Gerais. ${ }^{11}$

Já em se tratando da experiência estrangeira, na Argentina, em 21 de outubro de 2015, no caso Sandra v. Zoológico de Buenos Aires, a juíza Elena Libertori concedeu ordem de habeas corpus, determinando que a orangotango-fêmea, de nome Sandra, fosse enviada para um Centro de Grandes Primatas, localizado na Flórida, Estados Unidos, reconhecendo, expressamente, que ela era uma pessoa não-humana. ${ }^{12}$

Outro precedente argentino importante vai ocorrer em 3 de novembro de 2016, no caso Cecília v. Zoológico de Mendoza, no qual a juíza Maria Alejandra Maurício, da Província de Mendoza, reconheceu que a chimpanzé-fêmea, de nome Cecília, era titular do direito de liberdade corporal, concedendo ordem de habeas corpus para que o animal fosse transferido para um santuário no Brasil. ${ }^{13}$

Na Colômbia, em 26 de julho de 2017, a Suprema Corte de Justiça, no caso Chucho v. Zoo Barranquilla, decidiu, por meio do voto do Ministro Relator Luiz Armando Villanova, que o urso de óculos, conhecido como Chucho, era uma pessoa não-humana, titular do direito de liberdade corporal, determinando a sua transferência do Zoológico de Barranquilla para uma reserva de vida selvagem. ${ }^{14}$

Neste ano de 2020, retornando ao Brasil e à Salvador/BA, no caso Diego e outros v. Barcino, 23 gatos, representados pela guardiã Camila Oliveira, ingressaram com ação de obrigação de fazer, cumulada com indenização por dano moral, contra a empresa Barcino Esteve Construções e Incorporações Ltda., tendo o Juiz Érico Vieira, em 22 de janeiro de 2020, recebido a petição inicial e determinado a citação do réu para apresentar defesa, em 15 dias, reconhecendo, tacitamente, que os animais são sujeitos de direito, com capacidade para estarem em juízo, através de representação processual. Houve, posteriormente, designação de

\footnotetext{
${ }^{11}$ FERREIRA, Ana Conceição Barbuda Sanches Guimarães. Revista Brasileira de Direito Animal, v. 8, n. 12, 2013. Disponível em: https://portalseer.ufba.br/index.php/RBDA/article/view/8396/6013. Acesso em: 2 jan. 2020.

${ }^{12}$ PIETRZYKOWSKI, Tomasz. Personhood beyond humanism: animals, chimeras, autonomous agents and the law. Tradução: Krystyna Warchal. Cham: Springer, 2018. p. 87.

${ }^{13}$ MAURICIO, Maria Alejandra. Decisión del Habeas Corpus P-72.254/15 en favor de la Chimpancé Cecilia.

Revista Brasileira de Direito Animal, v. 11, n. 23, 2016. Disponível em: https://portalseer.ufba.br/index.php/RBDA/issue/view/1420/showToc. Acesso em: 26 dez. 2019.

${ }_{14}$ COLÔMBIA. AHC4806-2017. Supremo Tribunal da Colômbia. Disponível em: http://static.iris.net.co/semana/upload/documents/radicado-n-17001-22-13-000-2017-0. Acesso em: 2 jan. 20.
} 
audiência de conciliação entre as partes. Atualmente, a capacidade de ser dos gatos está sendo discutida perante o Tribunal de Justiça do Estado da Bahia. ${ }^{15}$

Ainda que a maioria desses casos não se enquadre no conceito estrito de precedente, servem para demonstrar a receptividade judicial à tese da capacidade processual dos animais, evidenciando um constante processo de judicialização do Direito Animal no Brasil e em outros países latino-americanos.

Por essa razão vale a pena expor, mais detidamente, o que a teoria processual brasileira tem a oferecer para alicerçar toda essa experiência insurgente.

\section{A CAPACIDADE PROCESSUAL NO DIREITO BRASILEIRO EM SUA TRÍPLICE CONFIGURAÇÃO}

O direito processual civil brasileiro adota uma tríplice configuração da capacidade processual (lato sensu): 1) capacidade de ser parte, 2) capacidade de estar em juízo (capacidade processual stricto sensu) e a 3) capacidade postulatória. ${ }^{16}$

A capacidade de ser parte (ius standi in iudicio) - para alguns chamada de personalidade processual ou personalidade judiciária" - "é a capacidade, ativa ou passiva, de ser sujeito da relação jurídica processual", ${ }^{18}$ ou seja, é a aptidão para exercer direitos e desempenhar deveres processuais, participando de uma relação jurídica processual ou assumindo uma situação jurídica processual.

Para Pontes de Miranda, a capacidade de ser parte é um "conceito anterior ao de capacidade processual", constituindo-se em um pressuposto pré-processual relacionado à

\footnotetext{
${ }^{15}$ BRASIL. 5a Vara Cível e Comercial de Salvador. Autos 8000905-50.2020.8.05.0001. Disponível em: https: / /www.anda.jor.br/2020/02/juiz-aceita-23-gatos-como-autores-de-acao-de-indenizacao-por-maustratos/. Acesso em: 19 fev. 2020.

${ }^{16}$ CÂMARA, Alexandre Freitas. O novo processo civil brasileiro. São Paulo: Editora Atlas, 2015. p. 28; MARINONI, Luiz Guilherme; ARENHART, Sérgio Cruz; MITIDIERO, Daniel. Novo curso de processo civil: tutela dos direitos mediante o procedimento comum. São Paulo: Editora Revista dos Tribunais, 2015. v. 2. p. 81.

${ }^{17}$ MARINONI, Luiz Guilherme; ARENHART, Sérgio Cruz; MITIDIERO, Daniel. Novo curso de processo civil: tutela dos direitos mediante o procedimento comum, p. 81; DIDIER JÚNIOR, Fredie. Curso de direito processual civil: introdução ao direito processual civil, parte geral e processo de conhecimento. 20 ed. Salvador: Editora Juspodivm, 2018. v. 1. p. 368.

${ }^{18}$ PONTES DE MIRANDA, Francisco Cavalcanti. Comentários ao Código de Processo Civil. Rio de Janeiro: Editora Forense; Brasília: INL, 1973. tomo I. p. 243.
} 
pretensão da tutela jurídica, uma vez que não se exige a titularidade do direito para que uma parte tenha capacidade processual. ${ }^{19}$

Todo aquele que é sujeito de direitos na ordem civil é dotado da capacidade de ser parte, seja pessoa, física ou jurídica, ou ente jurídico despersonalizado, como nos casos do espólio, massa falida, condomínio, sociedades sem personalidade jurídica, massa insolvente civil, instituições financeiras liquidadas extrajudicialmente, órgãos públicos de defesa do consumidor, órgãos públicos com prerrogativas próprias (Mesas de Câmaras Legislativas, Presidência de Tribunais, Chefias de Executivo, Ministério Público, Presidência de Comissões Autônomas etc.). ${ }^{20}$

Essa avaliação é sempre feita a priori, sem se perquirir sobre a relação jurídica de direito material controvertida, uma vez que ela é totalmente independente da legitimatio ad causam. ${ }^{21}$

A capacidade de estar em juízo (ou capacidade processual stricto sensu), por sua vez, é a aptidão para agir no processo de maneira autônoma, isto é, sem o acompanhamento de outra pessoa. Em outras palavras, é a aptidão para praticar pessoalmente atos processuais, independentemente de assistência ou representação. ${ }^{22}$

Conforme se depreende do artigo 70 do CPC/2015, a capacidade de estar em juízo corresponde, no plano processual, àquilo que a capacidade de fato ou de exercício corresponde no plano material, isto é, a aptidão para exercer "por si" os atos da vida civil. ${ }^{23}$

\footnotetext{
${ }^{19}$ PONTES DE MIRANDA, Francisco Cavalcanti. Comentários ao Código de Processo Civil, p. 244.

${ }^{20}$ Para Nelson Nery Jr. e Rosa Nery, "esses entes não tem personalidade jurídica, mas sim personalidade judiciária, isto é, podem estar em juízo como partes ou intervenientes." (NERY JUNIOR, Nelson; NERY, Rosa Maria de Andrade. Código de processo civil comentado. 11. ed. São Paulo: Editora Revista dos Tribunais, 2010).

${ }^{21}$ Segundo Fredie Didier Jr., "A capacidade de ser parte é atributo genérico; a legitimidade para agir é atributo específico, pois sempre diz respeito a determinada situação concreta. Todo sujeito de direito pode ser parte, mas ninguém é parte legítima para todas as causas. Todos podem demandar em juízo, mas ninguém está autorizado a levar, legitimamente, todas as situações concretas à apreciação do Poder Judiciário." (DIDIER JÚNIOR, Fredie. Pressupostos processuais e condições da ação: o juízo de admissibilidade do processo. São Paulo: Editora Saraiva, 2005. p. 124).

${ }^{22}$ DIDIER JÚNIOR, Fredie. Curso de direito processual civil: introdução ao direito processual civil, parte geral e processo de conhecimento, p. 371. Na mesma obra, Fredie Didier Júnior observa que a capacidade processual e a capacidade civil de exercício são autônomas e distintas: o sujeito pode ser processualmente capaz e material incapaz (como no caso do cidadão-eleitor de 16 anos para propor ação popular) ou processualmente incapaz e material capaz (como no caso réu preso revel, bem como ao réu revel citado por edital ou com hora certa, enquanto não for constituído advogado, hipóteses em que se exige a nomeação de curador especial, conforme art. 72, II, CPC).
}

${ }^{23}$ PONTES DE MIRANDA, Francisco Cavalcanti. Comentários ao Código de Processo Civil, p. 266. 
O CPC/2015 pouco acrescentou a essa matéria, uma vez que os atuais artigos 70 a 76 pouco diferem dos artigos $7^{\circ}$ a 13 do CPC/1973, e a incapacidade de estar em juízo continua a ser suprida pela representação ou pela assistência, na forma da lei.

De acordo com o Código Civil (CC/2002), reformado pela Lei $13.146 / 2015$, as pessoas naturais são absolutamente incapazes quando com menos de dezesseis anos de idade (artigo $3^{\circ}$ ) e são relativamente incapazes quando maiores de dezesseis e menores de dezoito anos, além dos ébrios habituais, os viciados em tóxico, aqueles que, por causa transitória ou permanente, não puderem exprimir sua vontade e os pródigos.

O suprimento da incapacidade processual stricto sensu dos absolutamente incapazes é feita pela representação; a complementação da capacidade processual dos relativamente incapazes se dá por meio da assistência, instituto jurídico que permite que o assistente e assistido atuem em conjunto. ${ }^{24}$

Por fim, tem-se a capacidade postulatória (ius postulandi), que é a capacidade técnica para postular em juízo, ${ }^{25}$ atribuída normalmente aos advogados, defensores públicos e membros do Ministério Público e, em alguns casos, a pessoas leigas, quando autorizadas pelo ordenamento jurídico, como acontece nos Juizados Especiais, nas causas trabalhistas e nos casos de habeas corpus, onde a capacidade processual é universal. ${ }^{26}$

Acontece que, a despeito dos precedentes judiciais latino-americanos, reconhecendo que os animais possuem capacidade processual lato sensu, ${ }^{27}$ o Código de Processo Civil (2015) e a doutrina processualista brasileiros continuam omissos sobre o tema. ${ }^{28}$

\footnotetext{
${ }^{24}$ TALAMINI, Eduardo; WAMBIER, Luiz Rodrigues. Curso avançado de processo civil. 16. ed. São Paulo: Editora Revista dos Tribunais, 2016. v. 1. p. 315.

${ }^{25}$ PONTES DE MIRANDA, Francisco Cavalcanti. Comentários ao Código de Processo Civil, p. 247.

${ }^{26}$ DIDIER JÚNIOR, Fredie. Curso de direito processual civil: introdução ao Direito Processual Civil, parte geral e processo de conhecimento, p. 389.

${ }^{27}$ SILVA, Tagore Trajano de Almeida. Capacidade de ser parte dos animais não-humanos: repensando os institutos da substituição e da representação processual. Revista Brasileira de Direito Animal, ano 4, n. 05, p. 323-352, jan./dez. 2009.

${ }^{28}$ Pontes de Miranda, em seu Tratado de direito privado, Tomo I, menciona que "Se o sistema jurídico, como sistema lógico, atribui direito a animais e a coisas, tais animais e coisas não são objeto - são sujeito; e exatamente em só se atribuírem direitos a homens e a entidades, de que se precisava para as relações da vida, consistiu uma das linhas da evolução jurídica." (Campinas: Bookseller, 2000. p. 220). Em uma rápida incursão nos clássicos manuais de Direito Processual Civil, nada se encontra a respeito da capacidade processual dos animais. Nada em Chiovenda, Carnelutti e Liebman. No Brasil, também nada se encontra em José Frederico Marques, Celso Agrícola Barbi, Ovídio Araújo Baptista da Silva, Moacyr Amaral Santos, Ernane Fidélis dos Santos, Humberto Theodoro Júnior, Cândido Rangel Dinamarco, Vicente Greco Filho, Arruda Alvim, Luiz Rodrigues Wambier e Eduardo Talamini, Luiz Guilherme Marinoni/Sérgio Cruz Arenhart e Daniel Mitidiero, Elpídio Donizetti e Daniel Amorim Assumpção Neves. Fredie Didier Júnior, ao menos até a $12^{\mathrm{a}}$ edição de seu Curso de direito processual civil: teoria geral do processo e processo de conhecimento (Salvador: Editora Juspodivm, 2010. v. 1), negava expressamente a capacidade de ser parte ao morto e aos animais (p. 233). 0 mesmo se verifica na monografia Pressupostos processuais e
} 


\section{O DECRETO 24.645/1934 E A CAPACIDADE PROCESSUAL DOS ANIMAIS NO} BRASIL

Tendo em vista que os juízes começam a admitir que animais têm capacidade de ser parte em juízo, por meio de assistentes ou representantes, torna-se necessário o desenvolvimento de uma dogmática processual que permita a operacionalização adequada dos novos direitos animais. ${ }^{29}$

É preciso saber, por exemplo, como os animais acessarão a justiça, ${ }^{30}$ ou seja, como eles serão identificados, quais adaptações procedimentais se farão necessárias, quais os casos de representação, assistência, substituição, litisconsórcio, etc. ${ }^{31}$ Dito de outra forma, é preciso pensar tutelas jurisdicionais diferenciadas para os animais não-humanos, enquanto titulares de direitos materiais.

Quanto à capacidade processual lato sensu dos animais, o primeiro (e único) diploma legal a tratar do tema foi o Decreto 24.645/1934, editado por Getúlio Vargas, o qual, em seu artigo $2^{\circ}, \$ 3^{\circ}$, estabelece, expressamente, que “Os animais serão assistidos em juízo pelos representantes do Ministério Público, seus substitutos legais e pelos membros das sociedades protetoras de animais."32

Esse Decreto foi editado com fundamento no Decreto 19.398 , de 11 de novembro de 1930, que instituiu o Governo Provisório, atribuindo ao Presidente da República o acúmulo

condições da ação: o juízo de admissibilidade do processo, ao menos na edição de 2005 (São Paulo: Editora Saraiva, 2005. p. 113). No entanto, em edições posteriores do Curso essas negativas desapareceram, o que faz transparecer que o processualista baiano não mais está convencido desse impedimento peremptório.

${ }^{29}$ ATAIDE JUNIOR, Vicente de Paula. Processo civil pragmático, Curitiba, 2013, 278 p. Tese (Doutorado em Direito) - Programa de Pós-Graduação em Direito da Universidade Federal do Paraná. p. 106-109.

${ }^{30}$ Para Fernando Araújo, "a questão dos direitos animais pode e deve ser dividida, visto que não parece já plausível atacar-se em bloco a ideia de uma atribuição genérica, que encontra já consagração legal num empenho na promoção universal e não-contingente de alguns aspectos do bem-estar animal. 0 que falta, em muitos casos, é a especificação de meios de acção que assegurem a defesa espontânea e individual de interesses de animais, complementando a diligência de instituições públicas e colectivas na defesa de interesses difusos de classes inteiras de animais (permitindo uma defesa individualmente tão efectiva como o é hoje a defesa dos interesses de menores, de deficientes e de pessoas colectivas)." (ARAÚJO, Fernando. A hora dos direitos dos animais. Lisboa: Almedina, 2003. p. 300).

${ }^{31}$ Nesse sentido, há recente julgado do Superior Tribunal de Justiça: 4a Turma, REsp 1713167/SP, Rel. Min. Luis Felipe Salomão, j. em 19/06/2018, p. em 09/10/2018. Para mais informações ver: https://www.conjur.com.br/2018-jun-19/stj-garante-direito-visita-animal-estimacao-separacao. Acesso em: 28 jul. 2018.

${ }^{32}$ SILVA, Tagore Trajano de Almeida. Capacidade de ser parte dos animais não-humanos: repensando os institutos da substituição e representação processual, p. 329. 
temporário das funções executivas e legislativas, até a promulgação de nova constituição, ${ }^{33}$ o que veio a ocorrer em 16 de julho de $1934 .{ }^{34}$

Acontece, porém, que o Decreto 24.645/1934 continua sendo objeto de controvérsia jurídica, uma vez que, em 18 de janeiro de 1991, o Chefe do Poder Executivo à época editou o Decreto 11/1991, revogando diversos atos governamentais promulgados por governos anteriores, dentre eles o Decreto 24.645/1934.

Quanto a isso, é preciso ressaltar que o Decreto $24.645 / 1934$ não foi editado como simples decreto regulamentar, como se tivesse natureza de ato administrativo, hierarquicamente inferior, mas como verdadeira lei ordinária, dotada de autonomia própria, estipulando direitos e deveres. ${ }^{35}$

A lei ocupa uma posição hierárquica superior ao decreto regulamentar, uma vez que, sendo fonte primária do direito, inova a ordem jurídica, ao passo que o decreto regulamentar, sendo fonte secundária, encontra seu fundamento de validade na lei. ${ }^{36}$

Caso se analise, com atenção, perceber-se-á que nenhum dos artigos do Decreto 24.645/1934 visa a executar disposições primárias contidas em lei preexistente. Ao contrário, esse diploma legal traz para o ordenamento jurídico uma série de normas primárias de Direito Penal (artigos $2^{\circ}$, $\S \S 1^{\circ}$ e $2^{\circ} ; 8^{\circ}$ e 15 ); de Direito Processual $\left(\operatorname{artigos} 2^{\circ}, \S 3^{\circ}\right.$ e 12 ) e de Direito Animal (como as que regulam a utilização de animais como tração de veículos).

Veja-se o impacto de se afirmar que "todos os animais existentes no País são tutelados pelo Estado" (artigo $1^{\circ}$ ), criando deveres estatais relevantíssimos.

O Decreto 24.645/1934, como um todo, é o primeiro estatuto jurídico geral do Direito Animal brasileiro, com normas jurídicas de variada natureza (penal, processual, administrativa/ambiental/animal), mas todas reservadas à Lei em sentido formal. ${ }^{37}$

\footnotetext{
33 “Art. 1..$^{\circ} \mathrm{O}$ Governo Provisório exercerá discricionariamente, em toda sua plenitude, as funções e atribuições, não só do Poder Executivo, como também do Poder Legislativo, até que, eleita a Assembleia Constituinte, estabeleça esta a reorganização constitucional do país." Disponível em: https://www2.camara.leg.br/legin/fed/decret/1930-1939/decreto-19398-11-novembro-1930-517605publicacaooriginal-1-pe.html. Acesso em: 13 jan. 2020.

${ }^{34}$ TÁCITO, Caio. Medidas provisórias na Constituição de 1988. Revista de Direito Público, Rio de Janeiro, p. 52-90, abr./jun. 1989.

${ }^{35}$ BENJAMIN, Antônio Herman de Vasconcellos e. A natureza no direito brasileiro: coisa, sujeito ou nada disso. Caderno jurídico da Escola Superior do Ministério Público do Estado de São Paulo, ano 1, v. 1, n. 02, p. 149-169, jul. 2001. p. 155; ARAÚJO, Fernando. A hora dos direitos dos animais, p. 288-302.

${ }^{36}$ MELLO, Celso Antônio Bandeira de. Curso de direito administrativo. 27. ed. São Paulo: Malheiros, 2010. p. 343.

${ }^{37}$ ATAIDE JUNIOR, Vicente de Paula; MENDES, Thiago Brizola Paula. Decreto 24.645/1934: breve história da “Lei Áurea" dos animais. Revista Brasileira de Direito Animal, v. 15, n. 2, p. 47-73, maio/ago. 2020. p. 62.
} 
Embora a denominação Decreto-Lei só tenha aparecido no ordenamento brasileiro com a Constituição outorgada de 1937 (artigos 12 e 13), ${ }^{38}$ fica evidente, por se tratar de ato emanado do Poder Executivo, quando este acumula funções do legislativo, a correspondência conceitual entre o dispositivo em análise e a definição de Decreto-Lei.

Mais adequado, portanto, seria chamar de Decreto-Lei 24.645/1934.

Mas essa disparidade terminológica é desinfluente na caracterização do Decreto 24.645 como autêntica Lei, dando o seu amplo caráter de inovação primária do ordenamento jurídico. ${ }^{39}$

Em parecer sobre a vigência do Decreto 24.645/1934, José Henrique Pierangeli afirma que "a lei nova recepciona conceitos e definições que não foram expressamente - e que só por essa forma poderiam sê-lo -, revogados" ${ }^{40}$, mesmo argumento apresentado pelo Promotor de Justiça Laerte Levai, para quem “com exceção feita ao superado sistema de penas ali previsto, o Decreto 24.645/1934 não foi revogado por nenhuma lei posterior, nem expressa, nem tacitamente." 41

Talvez a prova maior de que o Decreto 24.645/1934 continua em vigor é que ele tem sido utilizado para fundamentar importantes decisões do Supremo Tribunal Federal e do Superior Tribunal de Justiça, como nos votos do Ministro Carlos Velloso, na ADIn 1.856-6/RJ, que declarou a inconstitucionalidade de lei carioca que regulamentava a "rinha de galos", ${ }^{42}$ ou do Ministro Humberto Martins, no REsp 1115916/MG, que confirmou acórdão do Tribunal de Justiça de Minas Gerais, que impedia o uso de gás asfixiante no abate de cães, método considerado cruel. ${ }^{43}$

Assim, com o reconhecimento da vigência do Decreto 24.645/1934, ao menos nas suas disposições não-penais, ${ }^{44}$ pode-se afirmar que, no Brasil, a capacidade de ser parte dos animais é

\footnotetext{
${ }^{38}$ MENDES, Gilmar Ferreira; BRANCO, Paulo Gonet. Curso de direito constitucional. 10. ed. São Paulo: Editora Saraiva, 2015. p. 914.

${ }^{39}$ BENJAMIN, Antônio Herman Vasconcellos e. A natureza no direito brasileiro: coisa, sujeito ou nada disso, p. 155; ATAIDE JUNIOR, Vicente de Paula; MENDES, Thiago Brizola Paula. Decreto 24.645/1934: breve história da "Lei Áurea" dos animais, p. 63; CASTRO, João Marcos Adele y. Direito dos animais da legislação brasileira. Porto Alegre: Sergio Antônio Fabris Editor, 2006. p. 104.

${ }^{40}$ PIERANGELI, José Henrique. Parecer em direito penal ambiental. Justitia, São Paulo: Procuradoria Geral de Justiça; Associação Paulista do Ministério Público, v. 60, n. 181-184, p. 38-59, jan./dez. 1998. p. 56.

${ }^{41}$ LEVAI, Laerte Fernando. Direito dos animais. 2. ed. Campos do Jordão: Editora Mantiqueira, 2004. p. 30.

${ }^{42}$ STF, Plenário, ADIn 1856, Rel. Min. Carlos Velloso, j. em 03/09/1998, p. em 22/09/2000.

${ }^{43}$ STJ, 2 ${ }^{\text {a }}$ Turma, REsp 1115916-MG, Rel. Min. Humberto Martins, j. em 01/09/2009, p. em 18/09/2009.

44 Não se defende aqui a vigência integral do Decreto, da forma com que foi originalmente editado, pois, já na década de 1940, a Lei das Contravenções Penais (Decreto-Lei 3.688/41) transformou em contravenção penal a crueldade contra animais, cominando aos infratores penas e multas, nos termos de seu artigo 64, já revogado. Posteriormente, sob égide da atual Constituição, que trouxe expressa a proibição a crueldade (art. $225, \$ 1^{\circ}$, inciso VII), a Lei de Crimes Ambientais (Lei Federal 9.605/1998), nos termos do artigo 32, passou a
} 
prevista em lei, ou seja, o Direito Processual Civil brasileiro contempla a possibilidade de animais demandarem em juízo em nome próprio.

Nenhum outro País contempla norma jurídica semelhante.

Essa previsão legal reforça a constatação de que os animais são sujeitos de direito, dotados, em função do princípio do acesso à justiça (artigo $5^{\circ}, \mathrm{XXXV}, \mathrm{CF}$ ), da capacidade de ser parte.

Evidentemente, como os animais são incapazes de exercer pessoalmente os atos da vida civil (e de estarem no processo), há necessidade de suprir a sua incapacidade de estarem em juízo (incapacidade processual stricto sensu). ${ }^{45}$

É o artigo $2^{\circ}$, $\$ 3^{\circ}$ do Decreto 24.645/1934 que aponta os responsáveis por suprir essa incapacidade: (1) o Ministério Público; (2) os substitutos legais do animal (como o tutor/curador ou guardião); (3) os “membros" das sociedades protetoras de animais (as "ONG's" de proteção animal).

O titular do direito material é o próprio animal, que deverá ser representado/assistido em juízo por seus tutores/curadores ou guardiões, nos casos de animais domésticos ou domesticados, ou pelo Ministério Público ou sociedades protetoras, nos casos de animais abandonados ou silvestres, ou nos casos de conflito de interesse entre o animal e seu tutor/curador ou guardião, como nos casos de crueldade, abuso ou maus-tratos. ${ }^{46}$

considerar o abuso, os maus-tratos, o ferimento ou a mutilação de animais como crime, revogando, portanto, o artigo 64 da Lei de Contravenções, que regulava a mesma situação. Em outras palavras, somente os artigos (ou parte deles) que estabeleciam crimes e suas respectivas penas foram revogados, tacitamente, pelos dispositivos penais posteriores. 0 que não existe mais é o sistema penal idealizado pelo Decreto. Foram revogados, tacitamente, os artigos $2^{\circ}$ (caput e $\S \S 1^{\circ}$ e $2^{\circ}$ ), $8^{\circ}$ e 15 do Decreto, permanecendo em vigor os demais artigos, inclusive o $\$ 3^{\circ}$, do artigo $2^{\circ}$, como parte do atual estatuto jurídico geral dos animais.

${ }^{45}$ SILVA, Tagore Trajano de Almeida. Capacidade de ser parte dos animais não-humanos: repensando os institutos da substituição e representação processual, p. 342-343.

${ }^{46}$ GORDILHO, Heron Santana. Animal Abolitionism: Habeas Corpus for Great Apes. 2. ed. Salvador: EDUFBA, 2017. v. 1. p. 91 . Disponível em:

https://repositorio.ufba.br/ri/bitstream/ri/26540/1/AbolicionismoAnimal_port-ingl-RI-2017-EDUFBA.pdf Acesso em 15 maio 2020. 


\section{QUAIS A VANTAGENS EM SE RECONHECER A CAPACIDADE PROCESSUAL DOS ANIMAIS?}

Além do debate dogmático, com base nos elementos da ordem jurídica vigente, é preciso demonstrar as vantagens reais e pragmáticas que podem decorrer da mudança do status jurídico dos animais, possibilitando o seu acesso à justiça para defender direitos subjetivos.

É preciso saber se o acesso à justiça dos animais implicará em efetiva proteção de seus direitos e em um melhoramento de suas condições de vida, ou se, pelo contrário, não passará de um mero discurso simbólico ${ }^{47}$, sem qualquer alteração do atual estado de coisas. ${ }^{48}$

A primeira vantagem de se reconhecer a capacidade processual lato sensu dos animais é cultural, pois o fato dos animais poderem postular direitos perante os tribunais, para melhorar suas condições de vida, tem um significado simbólico importante, contribuindo com o nível de conscientização social das presentes e futuras gerações.

O processo judicial realiza direitos, e realizar direitos é reconhecer subjetividades, e a partir do momento em que a subjetividade animal é reconhecida pelo processo, passa a ser reconhecida pelo Direito, fazendo surgir novos valores, que passam a ser integrados à sociedade em constante transformação.

0 acesso à justiça aos animais vai criar um novo vocabulário, fazendo surgir novos institutos jurídicos, enriquecendo ainda mais a Ciência Jurídica, a partir da afirmação da dignidade para além do humano. ${ }^{49}$

\footnotetext{
${ }^{47}$ Sobre o caráter simbólico das alterações na legislação alemã: WACKE, Andreas. Protection os environment in roman law? Roman legal tradition, University of Glasgow School of Law, v .1, p. 1-24, 2002. Disponível em: www.romanlegaltradition.org/contents/2002/RLT-WACKE1.PDF. Acesso em: 28 jul. 2018; VÄRV, Age; KARU, Piia. The saller's liability in the event of lack of conformity of goods. Juridica international, Tartu/Estonia, Faculty of Law of the University of Tartu, v. 16, p. 85-93, 2009. Disponível em: http://www.juridicainternational.eu/index/2009/vol-xiv-2/the-sellers-liability-in-the-event-of-lackof-conformity-of-goods. Acesso em: 28 jul. 2018.

${ }^{48}$ Nesse sentido: MIGLIORE, Alfredo Domingues Barbosa. Personalidade jurídica dos grandes primatas. Belo Horizonte: Del Rey, 2012. p. 144-148; OST, François. A natureza à margem da lei: a ecologia à prova do direito. Lisboa: Instituto Piaget, 1995. p. 260-270.

${ }^{49}$ Segundo Richard Ryder, "A palavra especismo me ocorreu durante o banho, cerca de 35 anos atrás em Oxford. Era algo como o racismo ou sexismo - um preconceito moralmente irrelevante baseado em diferenças físicas. Com Darwin aprendemos que se somos animais humanos relacionados a todos os outros animais através da evolução, como, então, podemos justificar a nossa quase total opressão a todas as outras espécies? Todas as espécies de animais podem sofrer dor e angústia." (RYDER, Richard. Os animais e os direitos humanos. Revista Brasileira de Direito Animal, v. 3, n. 4, 2008. Disponível em: https://portalseer.ufba.br/index.php/RBDA/article/view/10458/7464. Acesso em: 19 fev. 2020.
} 
O Direito Animal traz consigo novos valores pacifistas e de alteridade, levando a refletir sobre a indiferença geral à violência diária que se pratica todos os dias contra criaturas indefesas.

Por outro lado, não se pode esquecer que essa escolha foi realizada em 1988, quando o Poder Constituinte Originário incumbiu ao Poder Público e à coletividade o dever de assegurar a efetividade do direito ao meio ambiente ecologicamente equilibrado, proibindo expressamente todas as práticas que coloquem em risco a função ecológica da fauna e da flora, que provoquem a extinção de espécies ou que submetam os animais à crueldade..$^{50}$

A outra vantagem é a realização prática do Direito Animal, por meio da sua judicialização. ${ }^{51}$

Imagine-se um animal doméstico que seja vítima de maus-tratos, e que em função disso, necessite de um tratamento de saúde vitalício, além de um aparelho protético. Seu responsável (o tutor, por exemplo) não tem condições financeiras para pagar as despesas médico-veterinárias. Poder-se-ia cogitar, desde logo, uma ação de reparação de danos contra o agressor fundada em danos à propriedade semovente.

Mas, o que garante que o responsável vai aplicar o valor da indenização recebida para o tratamento do animal? Ter-se-ia de contar com a sua compaixão ou sensibilidade, pois nem o Direito Civil, nem o Direito Ambiental, oferecem respostas a esse problema.

Do ponto de vista do Direito Animal, o próprio animal é o titular ao direito de reparação, gerando um patrimônio animal, o qual que será administrado ou fiscalizado pelas mesmas pessoas indicadas no artigo $2^{\circ}$, § $3^{\circ}$ do Decreto $24.645 / 1934$.

Reconhecida a capacidade de ser parte do animal, ele poderá demandar em juízo contra o seu agressor, assistido/representado por seu tutor/curador ou guardião, pelo Ministério Público ou pelas sociedades protetoras. Em caso de procedência do pedido, a indenização paga será administrada pelo assistente/representante, em proveito exclusivo do animal, com dever de prestação de contas conforme determinação judicial. ${ }^{52}$

\footnotetext{
${ }^{50}$ ATAIDE JUNIOR, Vicente de Paula. Introdução ao Direito Animal Brasileiro, p. 52.

${ }^{51 E ́}$ possível apontar três níveis de judicialização do Direito Animal: (1) a judicialização primária, pela qual os animais são defendidos como parte da fauna e da biodiversidade, ou seja, pela sua função ecológica; (2) a judicialização secundária, pela qual o animais passam a ser defendidos em juízo como indivíduos sencientes, porém, por meio da ações titularizadas pelos seus responsáveis humanos; (3) a judicialização terciária ou judicialização estrita do Direito Animal, por meio da qual os animais defendem seus direitos em juízo, assistidos ou representados na forma do art. $2^{\circ}$, $\S 3^{\circ}$ do Decreto 24.645/1934. É na judicialização terciária que o Direito Animal se realiza efetivamente, em sua integralidade, de acordo com suas regras e princípios próprios.

${ }^{52}$ Nesse sentido, foi proposta ação de reparação de danos perante a comarca de Cascavel/PR, em que o autor da demanda é JACK, cão maltrado pelo próprio tutor, assistido por uma ONG de defesa animal,
} 
Outras situações similares poderão ser pensadas e avaliadas, com foco da proteção de direitos subjetivos dos próprios animais.

Tanto a vantagem cultural, como a vantagem pragmática, parecem claras e observáveis, justificando uma elaboração teórica mais consistente.

\section{CONCLUSÃO}

Os juízes latino-americanos começam a reconhecer que os animais são sujeitos de direitos.

Como consequência lógica inexorável, esses animais, enquanto sujeitos de direitos subjetivos, são dotados da capacidade de ser parte.

Abre-se, portanto, o acesso à justiça aos animais não-humanos.

Por outro lado, por razões autoevidentes, os animais não possuem capacidade processual estrita para estarem em juízo.

O Brasil, nesse sentido, conta, ainda hoje, com o único diploma legal do mundo a tratar, expressamente, da capacidade processual lato sensu dos animais: o artigo $2^{\circ}, \S 3^{\circ}$, do Decreto 24.645/1934.

Tendo em vista que Decreto 24.645/1934 não pode ser considerado um simples decreto regulamentar, mas de um diploma legal que integra a ordem jurídica, com força de lei ordinária, foi ineficaz a sua revogação por meio do Decreto 11/1991.

Essa previsão legal coloca o Brasil, no âmbito latino-americano (e mundial), como o País dotado da legislação mais avançada em termos de tutela jurisdicional dos animais.

Cumpre, agora, também ao Brasil, liderar os precedentes judiciais que reconhecem a subjetividade animal e protegem seus direitos fundamentais por meio do processo.

\section{REFERÊNCIAS}

ARAÚJO, Fernando. A hora dos direitos dos animais. Lisboa: Almedina, 2003.

ATAIDE JUNIOR, Vicente de Paula; MENDES, Thiago Brizola Paula. Decreto 24.645/1934: breve história da "Lei Áurea" dos animais. Revista Brasileira de Direito Animal, v. 15, n. 2, p. 47-73, maio/ago. 2020.

evocando 0 art. $2^{\circ}, \$ 3^{\circ}$ do Decreto 24.645/1934. Petição inicial disponível em: http://www.direito.ufpr.br/portal/animaiscomdireitos/?p=3507. Acesso em: 29 fev. 2020. 
ATAIDE JUNIOR, Vicente de Paula. Processo civil pragmático, Curitiba, 2013, 278 p. Tese (Doutorado em Direito) - Programa de Pós-Graduação em Direito da Universidade Federal do Paraná.

ATAIDE JUNIOR, Vicente de Paula. Introdução ao Direito Animal Brasileiro. Revista Brasileira de Direito Animal, v. 13, n. 3, p. 48-76, set./dez. 2018. Disponível em:

https://portalseer.ufba.br/index.php/RBDA/article/download/28768/17032. Acesso em: 8 fev. 2020.

BENJAMIN, Antônio Herman de Vasconcellos e. A natureza no direito brasileiro: coisa, sujeito ou nada disso. Caderno jurídico da Escola Superior do Ministério Público do Estado de São Paulo, ano 1, v. 1, n. 02, p. 149-169, jul. 2001.

CÂMARA, Alexandre Freitas. O novo processo civil brasileiro. São Paulo: Editora Atlas, 2015.

CRUZ, Edmundo. Suíça - Habeas Corpus. Tradução: Carlos de Paula. Animal Legal \& Historical Center. Michigan State University. Disponível em: https://www.animallaw.info/case/suicahabeas-corpus. Acesso em: 5 jan. 2020.

DIDIER JÚNIOR, Fredie. Curso de direito processual civil: teoria geral do processo e processo de conhecimento. Salvador: Editora Juspodivm, 2010. v. 1.

DIDIER JÚNIOR, Fredie. Curso de direito processual civil: introdução ao direito processual civil, parte geral e processo de conhecimento. 20. ed. Salvador: Editora Juspodivm, 2018. v. 1.

DIDIER JÚNIOR, Fredie. Pressupostos processuais e condições da ação: o juízo de admissibilidade do processo. São Paulo: Editora Saraiva, 2005.

FERREIRA, Ana Conceição Barbuda Sanches Guimarães. Class action. Revista Brasileira de Direito Animal, v. 8, n. 12, 2013. Disponível em:

https://portalseer.ufba.br/index.php/RBDA/article/view/8396/6013. Acesso em: 2 jan. 2020.

GORDILHO, Heron. Wildlife and the Brazilian Abolitionist Movement. Michigan State University Journal of Animal Law, v. 5, p. 71, 2009. Disponível em:

https://www.animallaw. info/sites/default/files/Journal\%20of\%20Animal\%20Law\%20Vol205.pdf. Acesso em: 5 jan. 2020.

GORDILHO, Heron . Animal Abolitionism: Habeas Corpus for Great Apes. 2. ed. Salvador: EDUFBA, 2017. v. 1. 363p .Disponível em:

https://repositorio.ufba.br/ri/bitstream/ri/26540/1/AbolicionismoAnimal_port-ingl-RI-2017EDUFBA.pdf. Acesso em 15 maio 2020.

KANT, Immanuel. Doutrina do Direito. São Paulo: Ícone, 1993.

LEVAI, Laerte Fernando. Direito dos animais. 2. ed. Campos do Jordão: Editora Mantiqueira, 2004. 
MARINONI, Luiz Guilherme; ARENHART, Sérgio Cruz; MITIDIERO, Daniel. Novo Curso de Processo Civil: tutela dos direitos mediante o procedimento comum. São Paulo: Editora Revista dos Tribunais, 2015. v. 2.

MAURICIO, Maria Alejandra. Decisión del Habeas Corpus P-72.254/15 en favor de la Chimpancé Cecilia. Revista Brasileira de Direito Animal, v. 11, n. 23, 2016. Disponível em:

https://portalseer.ufba.br/index.php/RBDA/issue/view/1420/showToc. Acesso em: 26 dez. 2019.

MELLO, Celso Antônio Bandeira de. Curso de direito administrativo. 27. ed. São Paulo: Malheiros, 2010.

MENDES, Gilmar Ferreira; BRANCO, Paulo Gonet. Curso de direito constitucional. 10. ed. São Paulo: Editora Saraiva, 2015.

MIGLIORE, Alfredo Domingues Barbosa. Personalidade jurídica dos grandes primatas. Belo Horizonte: Del Rey, 2012.

NERY JUNIOR, Nelson; NERY, Rosa Maria de Andrade. Código de Processo Civil Comentado. 11. ed. São Paulo: Editora Revista dos Tribunais, 2010.

OST, François. A natureza à margem da lei: a ecologia à prova do direito. Lisboa: Instituto Piaget, 1995.

PIERANGELI, José Henrique. Parecer em direito penal ambiental. Justitia, São Paulo:

Procuradoria Geral de Justiça; Associação Paulista do Ministério Público, v. 60, n. 181-184, p. 3859, jan/dez. 1998.

PIETRZYKOWSKI, Tomasz. Personhood beyond humanism: animals, chimeras, autonomous agents and the law. Tradução: Krystyna Warchal. Cham: Springer, 2018.

PONTES DE MIRANDA, Francisco Cavalcanti. Comentários ao Código de Processo Civil. Rio de Janeiro: Editora Forense; Brasília: INL, 1973. tomo I.

PONTES DE MIRANDA, Francisco Cavalcanti. Tratado de direito privado. Campinas: Bookseller, 2000. tomo I.

REGAN, Tom. Nação do Direito Animal. Revista Brasileira de Direito Animal, v. 1, n. 1, 2006. Disponível em: https://portalseer.ufba.br/index.php/RBDA/article/view/10236/7292. Acesso em: 2 jan. 2020.

RYDER, Richard. Os animais e os direitos humanos. Revista Brasileira de Direito Animal, v. 3, n. 4. 2008: Disponível em: https://portalseer.ufba.br/index.php/RBDA/article/view/10458/7464. Acesso em: 13 jan. 2020.

SILVA, Tagore Trajano de Almeida. Capacidade de ser parte dos animais não-humanos: repensando os institutos da substituição e da representação processual. Revista Brasileira de Direito Animal, ano 4, n. 5, p. 323-352, jan./dez. 2009.

TALAMINI, Eduardo; WAMBIER, Luiz Rodrigues. Curso Avançado de Processo Civil. 16. ed. São Paulo: Editora Revista dos Tribunais, 2016. v. 1. 
THE ECONOMIST. 18 de dezembro de 2018. Seção internacional da edição impressa sob o título “Eles possuem direitos?". Disponível em:

https://www.economist.com/international/2018/12/22/gradually-nervously-courts-are-grantingrights-to-animals. Acesso em: 15 jan. 2020.

VÄRV, Age; KARU, Piia. The saller's liability in the event of lack of conformity of goods. Juridica international, Tartu/Estonia, Faculty of Law of the University of Tartu, v. 16, p. 85-93, 2009. Disponível em: http://www.juridicainternational.eu/index/2009/vol-xiv-2/the-sellers-liabilityin-the-event-of-lack-of-conformity-of-goods. Acesso em: 28 jul. 2018.

WACKE, Andreas. Protection os environment in roman law? Roman Legal Tradition, University of Glasgow School of Law, v, 1, p. 1-24, 2002. Disponível em:

www.romanlegaltradition.org/contents/2002/RLT-WACKE1.PDF. Acesso em: 28 jul. 2018.

WISE, Steven. O reconhecimento aos chimpanzés do direito de utilizar os writs do Habeas Corpus e do De Homina Replegiando. Revista Brasileira de Direito Animal, v. 6, n. 9, 2011. Disponível em: https://portalseer.ufba.br/index.php/RBDA/article/view/11741/8392. Acesso em: 2 jan. 2020.

\section{COMO FAZER REFERÊNCIA AO ARTIGO (ABNT):}

GORDILHO, Heron José de Santana. ATAIDE JUNIOR, Vicente de Paula. A capacidade processual dos animais no Brasil e na América Latina. Revista Eletrônica do Curso de Direito da UFSM, Santa Maria, RS, v. 15, n. 2, e42733, maio/ago. 2020. ISSN 1981-3694. DOI: http://dx.doi.org/10.5902/1981369442733. Disponível em: https://periodicos.ufsm.br/revistadireito/article/view/42733. Acesso em: dia mês. ano.

Direitos autorais 2020 Revista Eletrônica do Curso de Direito da UFSM

Editores responsáveis: Rafael Santos de Oliveira e Angela Araujo da Silveira Espindola

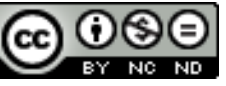

Esta obra está licenciada com uma Licença Creative Commons Atribuição-NãoComercial-SemDerivações 4.0 Internacional.

\section{SOBRE OS AUTORES}

\section{HERON GORDILHO}

Professor do corpo permanente do PPGD/UFBA, onde coordena o DINTER com a Universidade Federal de Sergipe (UFS) Faculdade Pio X, Centro Universitário UniRios e Faculdade de Administração e Negócios de Sergipe (FANESE). Professor do Corpo Permanente do PPGD/UCSAL.Doutor em Direito na Universidade Federal de Pernambuco. Estudos de pós-doutorado na Pace University Law School, Nova York, onde é coordenador regional do Instituto Brasileiro Americano de Direito e Meio Ambiente (BAILE). Professor visitante na École des Hautes Études en Science Sociales (EHESS/Paris/FR) como bolsista da CAPES. Professor colaborador do Master Derecho Animal \& Sociedad ( Universidad Autonoma de Barcelona/ESP). Diretor Internacional do Conselho Nacional da pesquisa em Direito (CONPEDI). Consultor da União Internacional para a Conservação da Natureza e dos Recursos Naturais (UICN). Consultor Ad Hoc da CAPES. Editor-Chefe da Revista do Programa de PósGraduação em Direito da UFBA. Editor-chefe da Revista Brasileira de Direito Animal. Membro da World Academy of Art \& 
ISSN 1981-3694

(DOI): $10.5902 / 1981369442733$

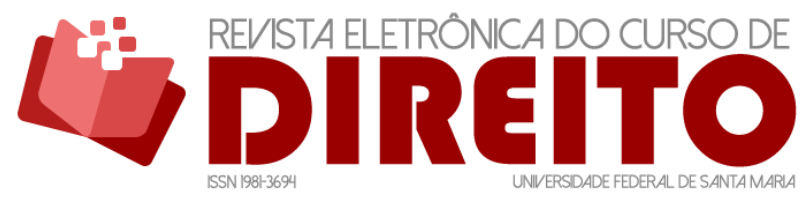

A CAPACIDADE PROCESSUAL DOS ANIMAIS NO BRASIL E NA AMÉRICA LATINA

HERON GORDILHO Vicente De PAUla ATAIDE JUNIOR

Science (WAAS). Desenvolve pesquisas nas seguintes áreas: Direito Animal, Direito Ambiental, Direito Internacional Público, Direito Constitucional. Coordenador do Núcleo de Pesquisa em Direito Animal, Ecologia e Pós-Humanismo.

\section{VICENTE DE PAULA ATAIDE JUNIOR}

Professor Adjunto do Departamento de Direito Civil e Processual Civil da Universidade Federal do Paraná (UFPR). Professor do Corpo Permanente do Programa de Pós-Graduação Stricto Sensu em Direito da Universidade Federal do Paraná. Doutor e Mestre em Direito Processual Civil pela Universidade Federal do Paraná. Pós-doutor em Direito Animal pela Universidade Federal da Bahia (UFBA). Pesquisador-Líder do ZOOPOLIS - Núcleo de Pesquisas em Direito Animal da Universidade Federal do Paraná. Pesquisador do EKOA: Direito, Movimentos Sociais e Natureza da Universidade Federal do Paraná. Coordenador do Programa de Extensão em Direito Animal da Universidade Federal do Paraná. Coordenador e Professor do Curso de Especialização em Direito Animal (EAD), da ESMAFE-PR/UNINTER. Juiz Federal titular da $2^{\mathrm{a}}$ Turma Recursal dos Juizados Especiais Federais do Paraná. Ex-Juiz Federal membro da Turma Regional de Uniformização da $4^{a}$ Região. Professor de Direito Processual Civil em diversas entidades, entre elas a Escola da Magistratura Federal do Paraná (ESMAFE/PR), a Escola da Magistratura do Paraná (EMAP), a Escola da Associação dos Magistrados do Trabalho do Paraná (EMATRAIX), a Fundação Escola do Ministério Público do Estado do Paraná (FEMPAR), a Escola Superior da Advocacia da OAB/PR (ESA-PR), o Instituto Romeu Bacellar e a Faculdade de Pinhais (FAPI-PR). Formador de Magistrados pela Escola Nacional de Formação e Aperfeiçoamento de Magistrados (ENFAM) e pela Escola da Magistratura do Tribunal Regional Federal da $4^{a}$ Região (EMAGIS). Foi Promotor de Justiça do Ministério Público de Rondônia (1996-2002). Ex-Diretor de Assuntos Jurídicos da Associação Paranaense dos Juízes Federais (APAJUFE), na gestão 2016/2018. Membro do Instituto Brasileiro de Direito Processual (IBDP) e Membro-Fundador do Instituto Paranaense de Direito Processual (IPDP). Membro da Comissão de Direito Socioambiental da Associação dos Juízes Federais do Brasil (AJUFE). 